\title{
Study on High Performance Control of the Machine-Side Converter of Doubly-Fed Turbines under Grid Distortion
}

\author{
Huanruo Qi ${ }^{1 *}$, Ningkang Zheng ${ }^{1}$, Xiangyang Yan $^{1}$ and Yilong Kang ${ }^{1}$ \\ ${ }^{1}$ State Grid Henan Economic Research Institute, Zhengzhou, Henan, 450000, China
}

\begin{abstract}
Two control strategies of DFIG under grid distortion are firstly summarized, namely, the control strategy of PI-R current controller based on dq reference frame and the control strategy of PI current controller based on the multiple rotating dq reference frame, and their advantages and disadvantages are analysed. On the basis of dynamic modelling of DFIG under grid distortion, in view of the defect that DFIG coupling is not considered in the control strategy of PI-R current controller based on dq reference frame, an improved control strategy considering motor coupling is proposed. In the end, the modelling and simulation of the unimproved and improved control strategies of PI-R current controller based on dq reference frame are carried out, and the simulation results verified the effectiveness of the improved control strategy.
\end{abstract}

\section{Preface}

Doubly-fed turbines are directly connected to the grid, hence the change of the grid environment will have a direct impact on them. The influence of grid harmonics on doubly-fed wind turbines is a problem not ignorable. The necessity of grid harmonics firstly makes this problem not ignorable. In modern grid, the application of power electronic converters has become a significant feature, but power electronic converters will inevitably induce harmonics with rich frequency. Grid standards such as IEEE 519-1992[1] and ERG5/4-1[2] of the International Electrotechnical Commission and Chinese national standard GB/T 14549-93[3] etc. clearly indicate that a certain proportion of harmonics is allowed in the industrial grid, especially at $6.6 \mathrm{kV}, 11 \mathrm{kV}$ and $20 \mathrm{kV}$ voltage class, 5 th and 7 th harmonics not exceeding $3 \%$ are allowed. The non-negligible effect of grid harmonics on doubly-fed wind turbines is also reflected in the fact that the low harmonic impedance of the generator itself is small, hence a small low harmonic voltage will produce a large current corresponding to the harmonic order, thus causing electromagnetic torque fluctuation and mechanical components vibration. Take the necessity above into account, more and more attention is paid to the optimal operation research of doubly-fed turbines under grid distortion. At present, the optimal control strategies of the machine-side converter under grid distortion can be mainly classified to two types, namely, the control strategy of PI-R current controller based on dq reference frame and the control strategy of PI current controller based on the multiple rotating dq reference frame. Nowadays control strategies under harmonic distortion are mainly evolved from the two control strategies above, such as the stator current harmonic direct closed loop control technology[4] for doubly fed wind turbines based on the resonant control, the selective harmonic elimination method[5] based on the resonant controller, the harmonic current control method[6] based on the multiple rotating dq reference frame.

DFIG is a cross-coupled complex system, and the motor coupling is not considered in the above two control strategies. On the basis of the control strategy of the machine-side converter of PI-R current controller based on dq reference frame, considering the coupling shutdown of the motor and implementing decoupling control to it, an improved control strategy is proposed and the design of PI-R current controller is produced in this paper. Finally, simulation results show that the improved control strategy is more effective and superior than the unimproved control strategy of the machine-side converter of PI-R control strategy based on dq reference frame.

\section{Conclusion of the two control strategies under harmonic distortion}

The control block diagram of the control strategy of the machine-side converter of PI-R current controller based on the multiple rotating dq reference frame is shown in Figure 1. The PI controller is used to control the rotor current in the multiple reference frames of dq, $-5 \mathrm{dq}$ and + $7 \mathrm{dq}$ rotating at the synchronous speed, -5times the synchronous speed and +7 times the synchronous speed respectively

"Corresponding author's e-mail: qihuanruo@outlook.com 


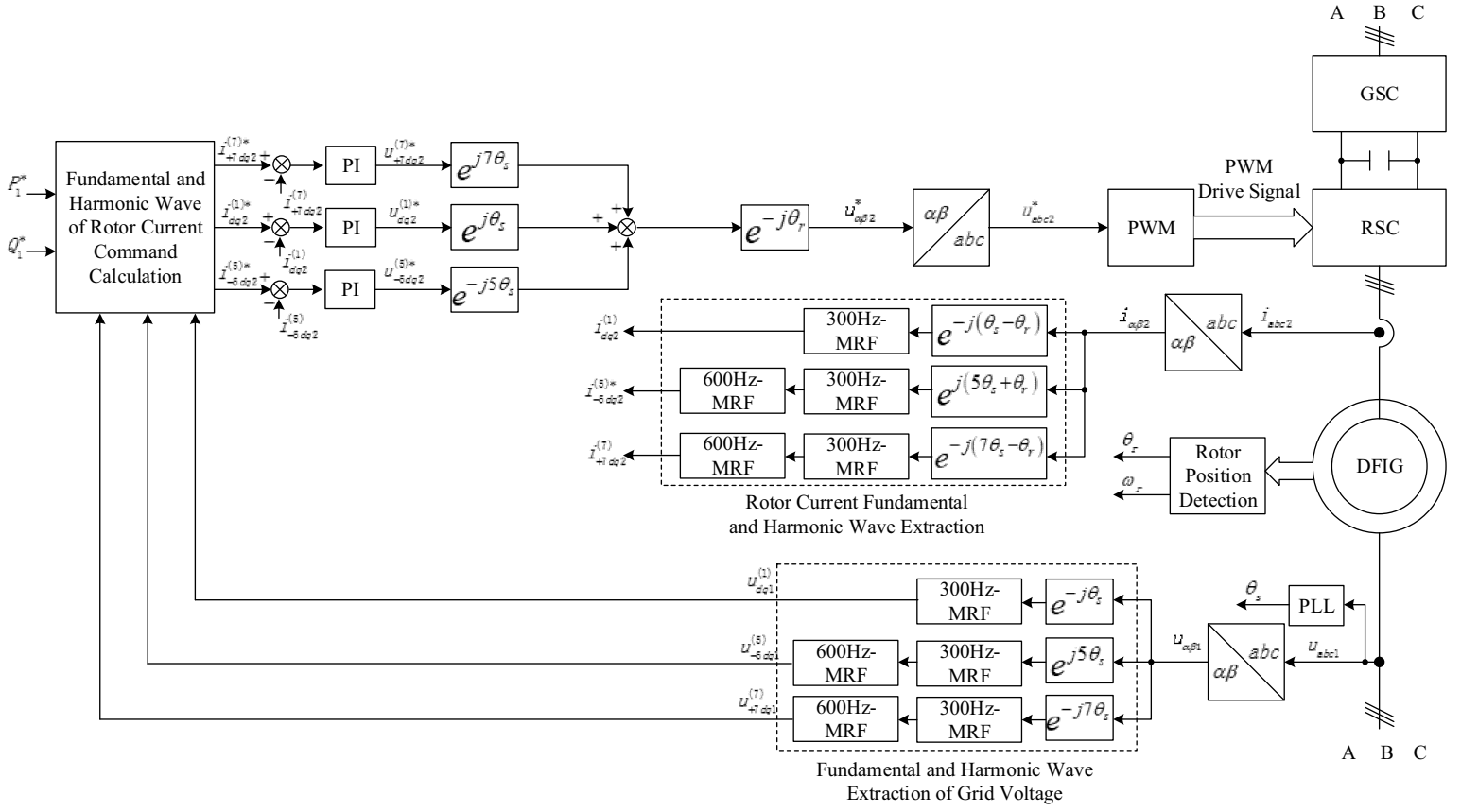

Figure 1. The control strategy of the machine-side converter of PI current controller based on the multiple rotating dq reference frame

PI controller is a proportional integral controller, which can only implement floating control to DC value but can do nothing to AC value. Due to this characteristic of the PI current controller, place the doubly-fed turbine models in the rotating reference frame of $\mathrm{dq},-5 \mathrm{dq}$ and +7 dq respectively, then the fundamental wave component, the 5th and 7th harmonic components represent DC characteristic respectively and the PI current controller is used to control each component. The obtained rotor voltage command values are that in the reference frame of $\mathrm{dq},-5 \mathrm{dq}$ and $+7 \mathrm{dq}$ respectively, which are converted to the rotor $\alpha \beta$ reference frame and added together to obtain the complete rotor voltage command value under harmonic conditions. Finally, through PWM modulation drive signal to drive the converter IGBT tube on or off.

The control block diagram of the control strategy of the machine-side converter of PI-R current controller based on dq reference frame is shown in figure 2. PI-R controller is used to control the rotor current in $\mathrm{dq}$ reference frame.

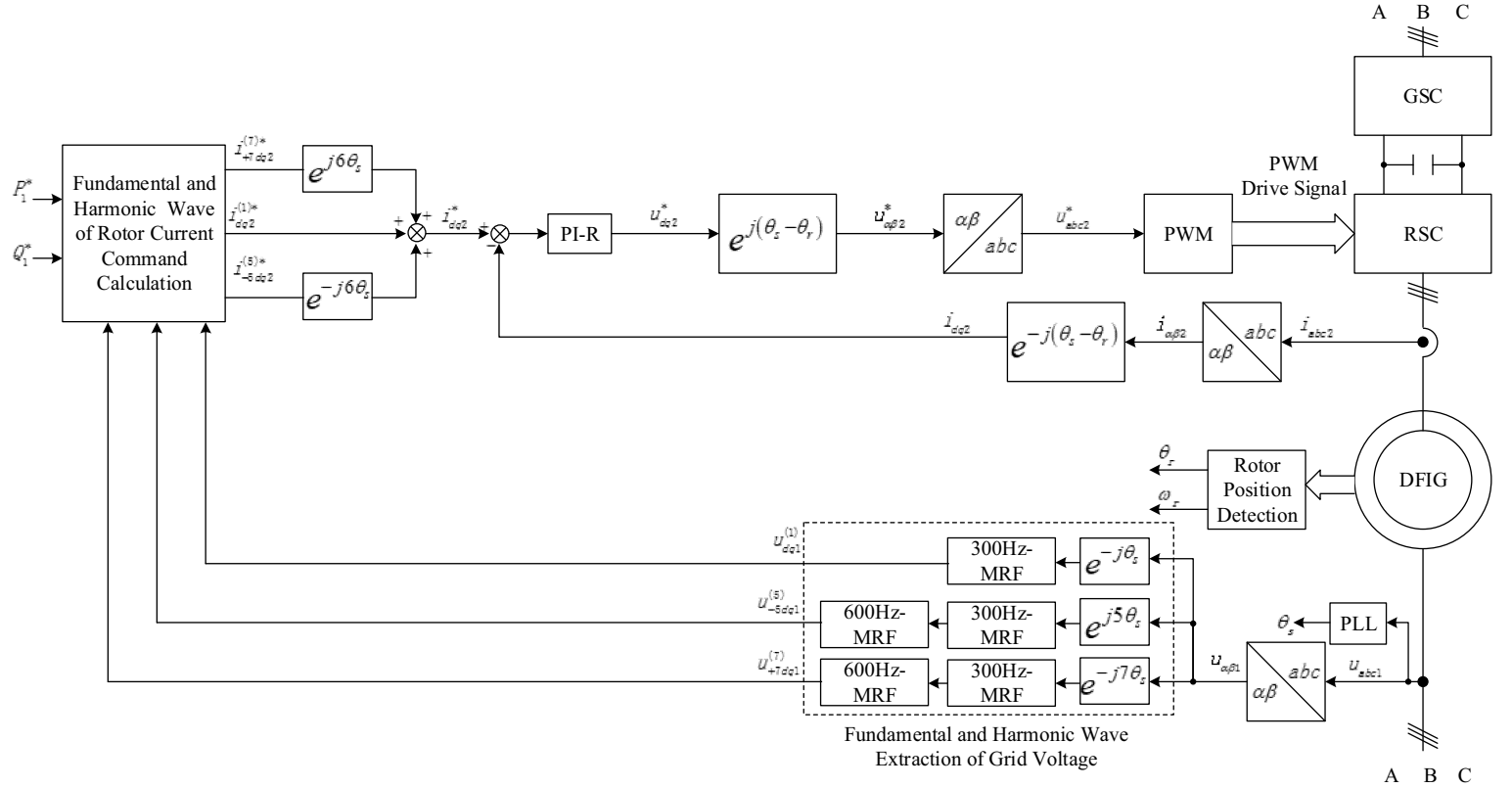

Figure 2. The control strategy of the machine-side converter of PI current controller based on the multiple rotating dq reference frame

The PI-R controller is called the proportional integral and resonant controller, and it consists of the PI proportional integral controller and the $\mathrm{R}$ resonant controller. The $\mathrm{R}$ resonant controller is a generalized $\mathrm{AC}$ integrator, which has a high control gain at the set resonant frequency, and a fast attenuation of the control gain outside the resonance frequency, with good frequency selectivity. The combination of PI and R controllers can not only 
realize the floating control of the $\mathrm{DC}$ value, but also the floating control of the $\mathrm{AC}$ value with a certain frequency. In the synchronously rotating dq reference frame, the fundamental wave component of DFIG is shown as DC value, meanwhile the 5th and 7th harmonics are shown as 6 times frequency component. Therefore, only a PI-R controller with resonant frequency of $6 \omega 1$ is needed to realize the synchronous control of the rotor current fundamental wave and the 5th and 7th harmonics. The voltage command value obtained by the current controller is the rotor voltage command value in $\mathrm{dq}$ reference frame, including the fundamental wave and harmonic component. It is then converted in the rotor $\alpha \beta$ reference frame to drive on or off the IGBT pipe of the machine-side converter by signal modulation.

The control strategy of the machine-side converter of PI current controller based on the multiple rotating dq reference frame is easy to achieve and dose not require the resonant controller. However, any harmonic control loop consists of a positive transformation of coordinates, harmonic extraction, PI controller and an inverse transformation of coordinates, thus when the harmonic order is much, it takes a lot of computation and a lot of digital resources. The control strategy of the machineside converter of PI current controller based on dq reference frame needs the resonant controller, but the number of PI controllers can be largely reduced. In addition, in the rotor current control loop, the control strategy of PI-R current controller does not need to extract the fundamental wave and each harmonic component of the rotor current, which reduces the delay of the control loop caused by harmonic extraction. For the control strategy of PI current controller based on the multiple rotating dq reference frame, the rotor current control loop must include the rotor current fundamental wave and each harmonic extraction part, thus the time delay induced by harmonic extraction may reduce the control precision.

\section{Dynamic modelling of DFIG under grid distortion}

The voltage equation of DFIG in dq reference frame is:

$$
\left\{\begin{array}{l}
u_{d q 1}=R_{1} i_{d q 1}+\frac{d \psi_{d q 1}}{d t}+j \omega_{1} \psi_{d q 1} \\
u_{d q 2}=R_{2} i_{d q 2}+\frac{d \psi_{d q 2}}{d t}+j \omega_{s} \psi_{d q 2}
\end{array}\right.
$$

The flux linkage equation is:

$$
\left\{\begin{array}{l}
\psi_{d q 1}=L_{1} i_{d q 1}+L_{m} i_{d q 2} \\
\psi_{d q 2}=L_{m} i_{d q 1}+L_{2} i_{d q 2}
\end{array}\right.
$$

Where, $\mathrm{u}_{\mathrm{dq} 1}$ and $\mathrm{u}_{\mathrm{dq} 2}$ are the stator and rotor voltage respectively, $i_{d q 1}$ and $i_{d q 2}$ are the stator and rotor current respectively, $\Psi_{\mathrm{dq} 1}$ and $\Psi_{\mathrm{dq} 2}$ are the stator and rotor flux linkage respectively, $\mathrm{R}_{1}$ and $\mathrm{R}_{2}$ are the stator and rotor resistance respectively, $\mathrm{L}_{\mathrm{m}}, \mathrm{L}_{1}$ and $\mathrm{L}_{2}$ are the mutual inductance and the stator and rotor inductance respectively, $\omega_{1}$ and $\omega_{\mathrm{r}}$ are the synchronous angular velocity and rotational angular velocity respectively.

After deformation, equation (2) can be obtained as follows:

$$
\psi_{d q 2}=\frac{L_{m} \psi_{d q 1}}{L_{1}}+\sigma L_{2} i_{d q 2}
$$

Where, $\sigma=1-\frac{L_{m}^{2}}{L_{1} L_{2}}$ is the magnetic flux leakage coefficient.

Substituting equation (3) into equation (1), the relationship between rotor voltage and rotor current can be obtained as follows:

$$
u_{d q 2}=R_{2} i_{d q 2}+\sigma L_{2}\left(\frac{d i_{d q 2}}{d t}+j \omega_{s} i_{d q 2}\right)+\frac{L_{m}}{L_{1}}\left(\frac{d \psi_{d q 1}}{d t}+j \omega_{s} \psi_{d q 1}\right)
$$

When considering harmonics, the grid voltage can be expressed as:

$$
u_{\alpha \beta 1}=U_{s m}^{(1)} e^{j\left(\omega_{1} t+\phi_{0}^{(1)}\right)}+U_{s m}^{(5)} e^{-j\left(5 \omega_{1} t+\phi_{0}^{(5)}\right)}+U_{s m}^{(7)} e^{j\left(7 \omega_{1} t+\phi_{0}^{(7)}\right)}
$$

Subscripts $\alpha \beta$ represents the corresponding reference frames, superscript (1), (5), (7) respectively represent the fundamental wave, the 5th and 7th harmonics, Usm is the amplitude of the grid voltage, $\varphi_{0}$ is the initial phase angle of the grid voltage vector.

Transforming the coordinate of the grid voltage, the transformation from the stationary reference frame to the dq synchronously rotating reference frame is:

$$
u_{d q 1}=u_{\alpha \beta 1} e^{-j \omega_{1} t}=u_{d q 1}^{(1)}+u_{-5 d q 1}^{(5)} e^{-j 6 \omega_{1} t}+u_{+7 d q 1}^{(7)} e^{j 6 \omega_{1} t}
$$

$\mathrm{U}^{(1)}{ }_{\mathrm{dq} 1}$ is the fundamental wave component of the grid voltage in $\mathrm{dq}$ reference frame, $\mathrm{U}^{(5)}{ }_{-5 \mathrm{dq} 1}$ is the fifth harmonic component of the grid voltage in the $-5 \mathrm{dq}$ reference frame, and $\mathrm{U}^{(7)}+7 \mathrm{dq} 1$ is the seventh harmonic component of the grid voltage in the $+7 \mathrm{dq}$ reference frame.

Similarly, the expressions of the stator current and stator flux linkage in dq reference frame are as follows:

$$
\begin{aligned}
& i_{d q 1}=i_{d q 1}^{(1)}+i_{-5 d q 1}^{(5)} e^{-j 6 \omega_{1} t}+i_{+7 d q 1}^{(7)} e^{j 6 \omega_{1} t} \\
& \psi_{d q 1}=\psi_{d q 1}^{(1)}+\psi_{-5 d q 1}^{(5)} e^{-j 6 \omega_{1} t}+\psi_{+7 d q 1}^{(7)} e^{j 6 \omega_{1} t}
\end{aligned}
$$

Substituting equations (6), (7) and (8) into equations (1) and (2), the stator voltage and flux linkage equation under harmonic conditions can be obtained as follows:

$$
\left\{\begin{array}{l}
u_{d q 1}^{(1)}=R_{1} i_{d q 1}^{(1)}+p \psi_{d q 1}^{(1)}+j \omega_{1} \psi_{d q 1}^{(1)} \\
u_{d q 2}^{(1)}=R_{2} i_{d q 2}^{(1)}+p \psi_{d q 2}^{(1)}+j \omega_{s} \psi_{d q 2}^{(1)} \\
u_{-5 d q 1}^{(5)}=R_{1} i_{-5 d q 1}^{(5)}+p \psi_{-5 d q 1}^{(5)}-j 5 \omega_{1} \psi_{-5 d q 1}^{(5)} \\
u_{-5 d q 2}^{(5)}=R_{2} i_{-5 d q 2}^{(5)}+p \psi_{-5 d q 2}^{(5)}-j \omega_{5 s} \psi_{-5 d q 2}^{(5)} \\
u_{+7 d q 1}^{(7)}=R_{1} i_{+7 d q 1}^{(7)}+p \psi_{+7 d q 1}^{(7)}+j 7 \omega_{1} \psi_{+7 d q 1}^{(7)} \\
u_{+7 d q 2}^{(7)}=R_{2} i_{+7 d q 2}^{(7)}+p \psi_{-7 d q 2}^{(7)}+j \omega_{7 s} \psi_{+7 d q 2}^{(7)}
\end{array}\right.
$$




$$
\left\{\begin{array}{l}
\psi_{d q 1}^{(1)}=L_{1} i_{d q 1}^{(1)}+L_{m} i_{d q 2}^{(1)} \\
\psi_{d q 2}^{(1)}=L_{2} i_{d q 2}^{(1)}+L_{m} i_{d q 1}^{(1)} \\
\psi_{-5 d q 1}^{(5)}=L_{1} i_{-5 d q 1}^{(5)}+L_{m} i_{-5 d q 2}^{(5)} \\
\psi_{-5 d q 2}^{(5)}=L_{2} i_{-5 d q 2}^{(5)}+L_{m} i_{-5 d q 1}^{(5)} \\
\psi_{+7 d q 1}^{(7)}=L_{1} i_{+7 d q 1}^{(7)}+L_{m} i_{+7 d q 2}^{(7)} \\
\psi_{+7 d q 2}^{(7)}=L_{2} i_{+7 d q 2}^{(7)}+L_{m} i_{+7 d q 1}^{(7)}
\end{array}\right.
$$

Where $\omega_{s}=\omega_{1}-\omega_{r}, \omega_{5 s}=5 \omega_{1}+\omega_{r}, \omega_{7 s}=7 \omega_{1}-\omega_{r}$.

\section{The control strategy of the machine- side converter of PI current controller based on dq reference frame}

Generally, according to the operation requirements of the grid and units, the control target of the machine-side converter can be set in one of the following four forms.

Goal 1: Balanced stator current to ensure the stator windings heat evenly.

Goal 2: Balanced rotor current to ensure the rotor windings heat evenly.

Goal 3: Balanced stator active power and stator reactive power.

Goal 4: Balanced stator reactive power and electromagnetic torque to reduce mechanical stress on wind turbines shafting.

Select different control targets. According to the motor equation, the command value of the rotor current under corresponding control targets can be inversely solved as follows:

Goal 1

$$
\left\{\begin{array}{l}
i_{-5 d q 2}^{(5)^{*}}=\frac{\psi_{-5 d q 1}^{(5)}}{L_{m}} \\
i_{+7 d q 2}^{(7)^{*}}=\frac{\psi_{+7 d q 1}^{(7)}}{L_{m}}
\end{array}\right.
$$

Goal 2

$$
\left\{\begin{array}{l}
i_{-5 d q 2}^{(5)^{*}}=0 \\
i_{+7 d q 2}^{(7)^{*}}=0
\end{array}\right.
$$

Goal 3

$$
\left\{\begin{array}{l}
i_{-5 d 2}^{(5)^{*}}=\frac{\psi_{-5 d 1}^{(5)}+7 \psi_{+7 d}^{(7)}}{L_{m}}-7 \lambda_{+7 d} i_{d 2}^{(1)}-7 \lambda_{+7 q} i_{q 2}^{(1)} \\
i_{-5 q 2}^{(5)^{*}}=\frac{\psi_{-5 q 1}^{(5)}-7 \psi_{+7 q}^{(7)}}{L_{m}}+7 \lambda_{+7 q} i_{d 2}^{(1)}+7 \lambda_{+7 d} i_{q 2}^{(1)} \\
i_{+7 d 2}^{(7)^{*}}=\frac{-5 \psi_{-5 d 1}^{(5)}+\psi_{+7 d}^{(7)}}{L_{m}}+5 \lambda_{-5 d} i_{d 2}^{(1)}+5 \lambda_{-5 q} i_{q 2}^{(1)} \\
i_{+7 q 2}^{(7)^{*}}=\frac{5 \psi_{-5 q 1}^{(5)}+\psi_{+7 q}^{(7)}}{L_{m}}-5 \lambda_{-5 q} i_{d 2}^{(1)}+5 \lambda_{-5 d} i_{q 2}^{(1)}
\end{array}\right.
$$

In the equation above, $\lambda_{-5 d}=\frac{\psi_{-5 d 1}^{(5)}}{\psi_{d 1}^{(1)}}, \lambda_{-5 q}=\frac{\psi_{-5 q 1}^{(5)}}{\psi_{d 1}^{(1)}}$,

$\lambda_{+7 d}=\frac{\psi_{+7 d 1}^{(7)}}{\psi_{d 1}^{(1)}}, \lambda_{+7 q}=\frac{\psi_{+7 q 1}^{(7)}}{\psi_{d 1}^{(1)}}$.

Goal 4

$$
\left\{\begin{array}{l}
i_{-5 d 2}^{(5) *}=\frac{-2 \psi_{-5 d 1}^{(5)}+4 \psi_{+7 d 1}^{(7)}}{L_{m}}+\left(3 \lambda_{-5 d}-4 \lambda_{+7 d}\right) i_{d 2}^{(1)}+\left(3 \lambda_{-5 q}-4 \lambda_{+7 q}\right) i_{q 2}^{(1)} \\
i_{-5 q 2}^{(5) *}=\frac{-2 \psi_{-5 q 1}^{(5)}-4 \psi_{+7 q 1}^{(7)}}{L_{m}}+\left(3 \lambda_{-5 q}+4 \lambda_{+7 q}\right) i_{d 2}^{(1)}-\left(3 \lambda_{-5 d}-4 \lambda_{+7 d}\right) i_{q 2}^{(1)} \\
i_{+7 d 2}^{(7) *}=\frac{-2 \psi_{-5 d 1}^{(5)}+4 \psi_{+7 d 1}^{(7)}}{L_{m}}+\left(2 \lambda_{-5 d}-3 \lambda_{+7 d}\right) i_{d 2}^{(1)}+\left(2 \lambda_{-5 q}-3 \lambda_{+7 q}\right) i_{q 2}^{(1)} \\
i_{+7 q 2}^{(7) *}=\frac{2 \psi_{-5 q 1}^{(5)}+4 \psi_{+7 q 1}^{(7)}}{L_{m}}-\left(2 \lambda_{-5 q}+3 \lambda_{+7 q}\right) i_{d 2}^{(1)}+\left(2 \lambda_{-5 d}+3 \lambda_{+7 d}\right) i_{q 2}^{(1)}
\end{array}\right.
$$

See literature [8] for its theoretical derivation.

It can be seen from equation (4) that the $d$ and $q$ axis components of the rotor voltage are related not only to the $\mathrm{d}$ and $\mathrm{q}$ axis components of the rotor current, but also to the $\mathrm{q}$ and $\mathrm{d}$ axis components of the stator flux linkage.

Considering the harmonic, the rewritten formula (4) can clearly express the coupling relationship by writing the $\mathrm{D}$ and $\mathrm{Q}$ axes separately:

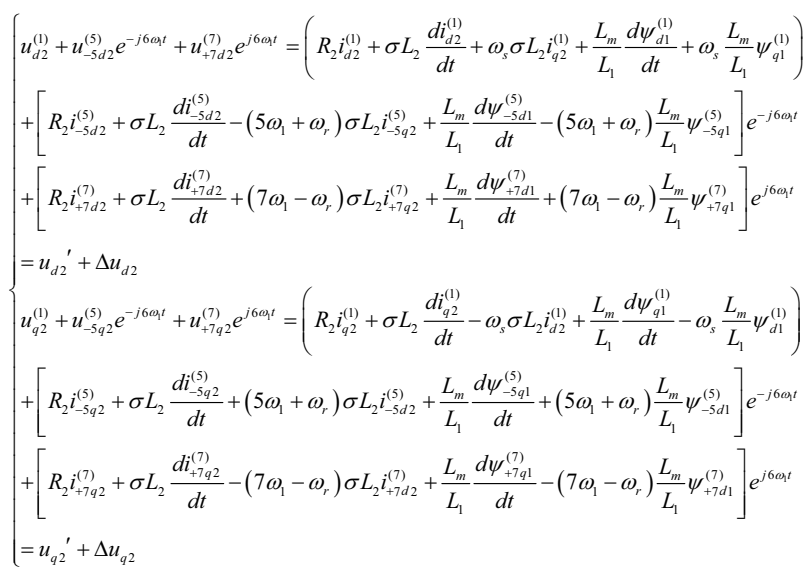

Where,

$$
u_{d 2}{ }^{\prime}=G_{P I R}(s)\left(i_{d 2}^{*}-i_{d 2}\right)
$$

$u_{q 2}{ }^{\prime}=G_{P I R}(s)\left(i_{q 2}^{*}-i_{q 2}\right)$ is the output of the PIR controller in dq reference frame, $G_{P I R}(s)$ is the transfer function of the PIR controller, $\Delta u_{d 2}$ and $\Delta u_{q 2}$ are the compensation terms of the rotor voltage in dq reference frame. Considering the constant amplitude of the stator flux fundamental wave and each harmonic wave during the steady-state operation of the unit, the compensation terms can be simplified as follows:

$$
\left\{\begin{aligned}
\Delta u_{d 2}= & \omega_{s} \sigma L_{2} i_{q 2}-6 \omega_{1} \sigma L_{2}\left(i_{-s q 2}^{(5)} e^{-j 6 \omega_{1} t}-i_{+7 q 2}^{(7)} e^{j 6 \omega_{9} t}\right) \\
& +\frac{L_{m}}{L_{1}}\left(\omega_{s} \psi_{q 1}^{(1)}-\omega_{5 s} \psi_{-s q 1}^{(5)} e^{-j 6 \omega_{1} t}+\omega_{7 s} \psi_{+7 q 1}^{(7)} e^{j 6 \omega_{1} t}\right) \\
\Delta u_{q 2}= & -\omega_{s} \sigma L_{2} i_{d 2}+6 \omega_{1} \sigma L_{2}\left(i_{-s d 2}^{(5)} e^{-j 6 \omega_{1} t}-i_{+7 d 2}^{(7)} e^{j 6 \omega_{1} t}\right) \\
& -\frac{L_{m}}{L_{1}}\left(\omega_{s} \psi_{d 1}^{(1)}-\omega_{5 s} \psi_{-s d 1}^{(5)} e^{-j 6 \omega_{1} t}+\omega_{7 s} \psi_{+7 d 1}^{(7)} e^{j 6 \omega_{1} t}\right)
\end{aligned}\right.
$$

The control block diagram of the improved control strategy of the machine-side converter of PI-R current controller based on $\mathrm{dq}$ reference frame is shown in 
Figure 3. According to different control targets, transfer the fundamental wave command in dq reference frame, the 5 th harmonic command in $-5 \mathrm{dq}$ reference frame and +7 th harmonic command in $+7 \mathrm{dq}$ reference frame calculated by the fundamental wave and harmonic rotor current command calculation module to the current command value in dq reference frame, the rotor current is directly transformed in $\mathrm{dq}$ reference frame as the feedback value without the fundamental wave and harmonic extraction, after the voltage compensation of coupling term, the command value of rotor voltage in $\mathrm{dq}$ reference frame is obtained, finally coordinate transformation and PWM signal modulation are adopted to drive on and off the IGBT pipe of the machine-side converter, so as to realize power and harmonic control under the specified control target of DFIG.

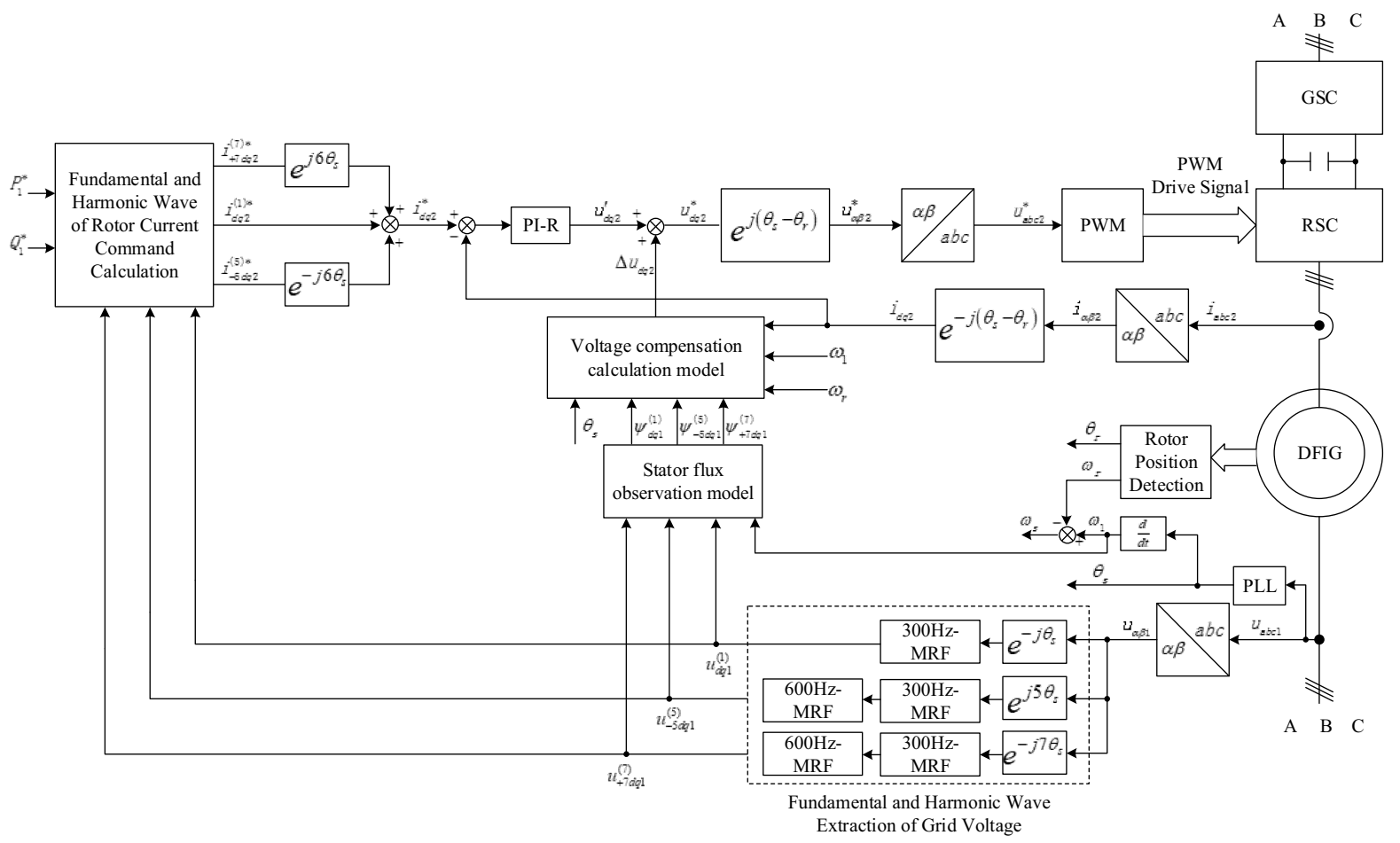

Figure 3. The improved control strategy of machine-side converter of PI-R current controller based on dq reference frame

The compensation voltage calculation model based on dq reference frame is shown in Figure 4. After the transformation of equation (16), in the calculation of compensation voltage, only the 5 th and 7 th harmonic

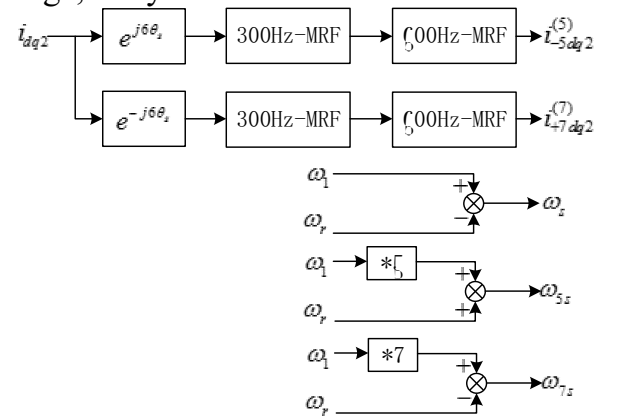

components of the rotor current need to be extracted instead of the fundamental component, which reduces the complexity of the control system and avoids the delay caused by the fundamental wave extraction.

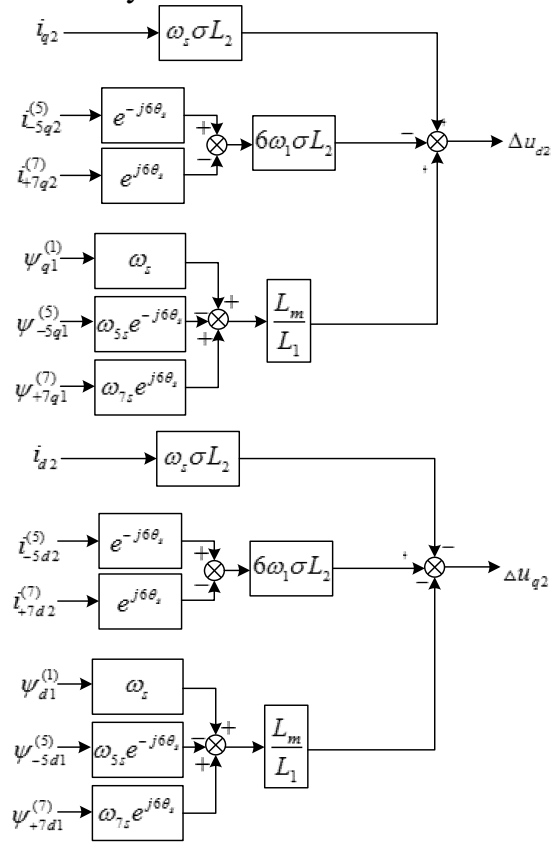

Figure 4. Compensation voltage calculation model based on dq reference frame 


\section{Design of PI-R controller}

Combined with the mathematical model of DFIG in section 2 and the control strategy in section 3 , the structure block diagram of the doubly-fed wind turbine control system in dq reference frame can be drawn, as shown in Figure 5.

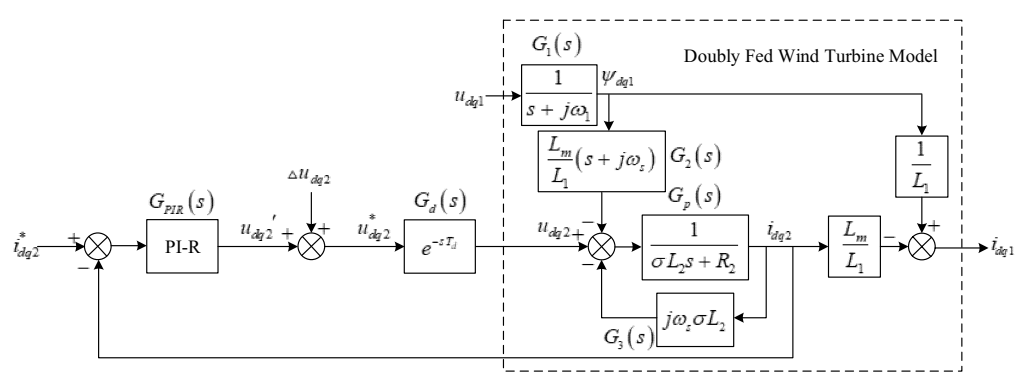

Figure 5. The structure block diagram of doubly-fed wind turbine control system in dq reference frame

In the figure above, the dotted line represents the DFIG model, and $G_{1}(s), G_{2}(s), G_{3}(s)$ and $G_{p}(s)$ are the four square transfer functions in the doubly fed generator model. $G_{d}(s)$ is the sampling period calculation delay function induced by digital control system. The delay time $T_{d}$ is equal to the sampling period and also equal to half of the switching period. According to the converter parameters in Table 1, the sampling period in this paper is $250 \mu \mathrm{s} . \quad G_{P I R}(s)=K_{P}+\frac{K_{I}}{s}+\frac{2 K_{R} \omega_{c} s}{s^{2}+2 \omega_{c} s+\omega_{0}^{2}}$ Is PI-R controller transfer function.

Assuming that the compensation term can accurately compensate to realize good decoupling of the dq axis, and the compensation term and the coupling term can be ignored, the current loop structure block diagram is shown in Figure 6.

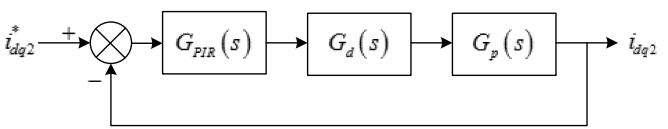

Figure 6. The current loop structure diagram of doubly-fed wind turbine control system

At this point, the rotor current loop open-loop transfer function is:

$$
\begin{aligned}
G_{i 2 o}(s) & =G_{P I R}(s) G_{d}(s) G_{p}(s)=\left(K_{P}+\frac{K_{I}}{s}+\frac{2 K_{R} \omega_{c} s}{s^{2}+2 \omega_{c} s+\omega_{0}^{2}}\right) \frac{1}{\sigma L_{2} s+R_{2}} e^{-s T_{d}} \\
& =\left\{\frac{K_{I}}{R_{2}} \frac{\left(\frac{K_{P}}{K_{I}}+\frac{1}{s}\right)}{(\tau s+1)}+\frac{K_{I}}{R_{2}} \frac{\frac{2 K_{R} \omega_{c} s}{K_{I} \omega_{0}^{2}}}{(\tau s+1)\left[\left(\frac{s}{\omega_{0}}\right)^{2}+\frac{2 \omega_{c}}{\omega_{0}^{2}} s+1\right]}\right\} e^{-s T_{d}} \\
& =\frac{K_{I}}{R_{2}} \frac{\frac{K_{P}}{K_{I} \omega_{0}^{2}} s^{3}+\frac{2\left(K_{P}+K_{R}\right) \omega_{c}+K_{I}}{K_{I} \omega_{0}^{2}} s^{2}+\left(\frac{K_{P}}{K_{I}}+\frac{2 \omega_{c}}{\omega_{0}^{2}}\right) s+1}{s(\tau s+1)\left[\left(\frac{s}{\omega_{0}}\right)^{2}+\frac{2 \omega_{c}}{\omega_{0}^{2}} s+1\right]} e^{-s T_{d}}
\end{aligned}
$$

Where, $\tau=\frac{\sigma L_{2}}{R_{2}}$ is the rotor side time constant. Substituting $s=j \omega_{c r}$ in equation (17), the rotor current loop open-loop transfer function in the crossover frequency $\omega_{\mathrm{cr}}$ is:

$$
G_{i 2 o}\left(j \omega_{c r}\right)=\frac{K_{I}-\frac{\left[K_{I}+2 \omega_{c}\left(K_{P}+K_{R}\right)\right] \omega_{c r}^{2}}{\omega_{0}^{2}}+j\left(K_{P} \omega_{c r}-K_{P} \frac{\omega_{c r}^{3}}{\omega_{0}^{2}}+K_{I} \frac{2 \omega_{c} \omega_{c r}}{\omega_{0}^{2}}\right)}{j R_{2} \omega_{c r}\left(j \omega_{c r} \tau+1\right)\left[1-\left(\frac{\omega_{c r}}{\omega_{0}}\right)^{2}\right]} e^{-j \omega_{c r} T_{d}}
$$

In general, if the crossover frequency $\omega_{c r}$ is slightly greater than the resonant frequency $\omega_{0}$ of PI-R controller, they can be considered to be approximately equal, so in the real part of the above formula molecule $K_{I}-K_{I} \frac{\omega_{c r}^{2}}{\omega_{0}^{2}} \approx 0$. And since $2 \omega_{c} \prec \prec \omega_{0}$, in the imaginary part $K_{I} \frac{2 \omega_{c} \omega_{c r}}{\omega_{0}^{2}} \approx 0$. According to DFIG parameter, it can be calculated that the rotor time constant is about 11 , which is much greater than 1 . Therefore, the term $\left(j \omega_{c r} \tau+1\right)$ in the denominator of the above formula can be simplified to $j \omega_{c r} \tau$. After the above treatment, the frequency characteristic expression of the rotor current loop open loop transfer function at the crossover frequency can be simplified as:

$$
G_{i 2 o}\left(j \omega_{c r}\right) \approx \frac{2 \omega_{c}\left(K_{P}+K_{R}\right)\left(\frac{\omega_{c r}}{\omega_{0}}\right)^{2}+j K_{P} \omega_{c r}\left[\left(\frac{\omega_{c r}}{\omega_{0}}\right)^{2}-1\right]}{\omega_{c r}^{2} \sigma L_{2}\left[1-\left(\frac{\omega_{c r}}{\omega_{0}}\right)^{2}\right]} e^{-j \omega_{c r} T_{d}}
$$

The phase margin of the rotor current loop open loop transfer function at the crossover frequency is expressed as:

$$
\phi=\pi+\angle G_{i 2 o}\left(j \omega_{c r}\right) \approx \arctan \left\{\frac{K_{P} \omega_{c r}}{2 \omega_{c}\left(K_{P}+K_{R}\right)}\left[1-\left(\frac{\omega_{0}}{\omega_{c r}}\right)^{2}\right]\right\}-\omega_{c r} T_{d}
$$

The gain of the open-loop transfer function at the open-loop crossing frequency should be 1 , that is: 


$$
\begin{aligned}
\left|G_{i 2 o}\left(j \omega_{c r}\right)\right| & \approx \mid \frac{2 \omega_{c}\left(K_{P}+K_{R}\right)\left(\frac{\omega_{c r}}{\omega_{0}}\right)^{2}+j K_{P} \omega_{c r}\left[\left(\frac{\omega_{c r}}{\omega_{0}}\right)^{2}-1\right]}{\omega_{c r}^{2} \sigma L_{2}\left[1-\left(\frac{\omega_{c r}}{\omega_{0}}\right)^{2}\right]} e^{-j \omega_{c r} T_{d}} \\
& =\left|\frac{2 \omega_{c}\left(K_{P}+K_{R}\right)\left(\frac{\omega_{c r}}{\omega_{0}}\right)^{2}+j K_{P} \omega_{c r}\left[\left(\frac{\omega_{c r}}{\omega_{0}}\right)^{2}-1\right]}{\omega_{c r}^{2} \sigma L_{2}\left[1-\left(\frac{\omega_{c r}}{\omega_{0}}\right)^{2}\right]}\right|=1
\end{aligned}
$$

It can be deduced that:

$$
\omega_{c}\left(K_{P}+K_{R}\right) \approx 0.5 \omega_{c r}\left[1-\left(\frac{\omega_{0}}{\omega_{c r}}\right)^{2}\right] \sqrt{\left(\omega_{c r} \sigma L_{2}\right)^{2}-K_{P}^{2}}
$$

Combining equations (20) and (22), it can be concluded that:

$$
K_{P} \approx \frac{\sigma L_{2} \omega_{c r}}{\sqrt{1+\frac{1}{\tan \left(\phi+\omega_{c r} T_{d}\right)}}}
$$

Based on the above derivation, the design steps of PI$\mathrm{R}$ current controller in dq reference frame are as follows:

1) Select appropriate phase margin and open loop crossover frequency. The generally recommended phase margin $\varphi$ should be between $30^{\circ}$ and $60^{\circ}$ [9]. The recommended open-loop crossover frequency $\omega_{c r}$ is between $1 / 10$ and $1 / 5$ switching frequency.

2) By substituting the set phase margin and the openloop crossover frequency into equation (19), the parameter value $K_{p}$ of PI-R controller can be obtained.

3) Substitute $K_{p}, \varphi, \omega_{c r}$ into equation (22) to get the value of $\left(K_{P}+K_{R}\right) \omega_{c}$.

4) According to the operational accuracy of the digital processor, select the smaller $\omega_{c}$, usually the recommended PI-R controller cutoff frequency is between $2 \mathrm{rad} / \mathrm{s}$ and $10 \mathrm{rad} / \mathrm{s}$.

5) Calculate $K_{R}$ from the known $K_{p} 、 \omega_{c} 、\left(K_{p}+K_{R}\right)$ $\omega_{c}$

6) In PI - R controller, the parameters of PI controller mainly perform floating control to the fundamental component in $\mathrm{dq}$ reference frame, $\mathrm{R}$ controller parameters under the fundamental frequency effect is very small.Therefore, When determining the $\mathrm{K}_{\mathrm{I}}$ parameter value in PI-R controller, make it consistent with the $\mathrm{K}_{\mathrm{I}}$ parameter value in PI controller.See literature [10] for the parameter design method of PI controller.

7) Check whether the solved PI-R parameters meet the requirements of steady and dynamic performance of the control system. If not, adjust the phase margin and the selection of open loop crossover frequency and cutoff frequency, and repeat the above steps until the steady and dynamic performance of the system is optimal.

In accordance with the above steps, the phase margin $\varphi$ in this paper is selected as $30^{\circ}$, the open loop crossover frequency $\omega_{c r}$ is selected as $1 / 6$ switching frequency, namely $333 \times 2 \pi \mathrm{rad} / \mathrm{s}$, and the cut-off frequency $\omega_{c}$ is selected as $5 \mathrm{rad} / \mathrm{s}$. The parameters of the PI-R controller are obtained as $K_{P}=18 、 K_{l}=405 、 K_{R}=942$.

Controlling the rotor current according to the designed PI and PI-R controller parameters, the amplitude-frequency characteristic curve of the closed loop transfer function $\frac{i_{d q 2}}{i_{d q 2}^{*}}=\frac{G_{i 2 o}(s)}{1+G_{i 2 o}(s)}$ of the rotor current loop is shown in Fig.7.

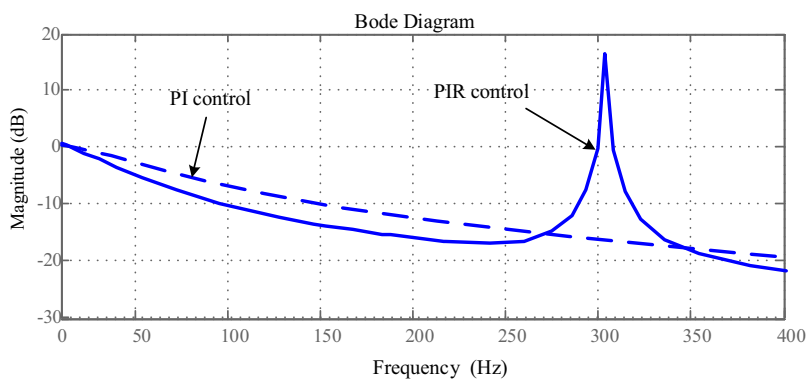

Figure 7. Amplitude-frequency characteristics of the closedloop transfer function of rotor current

It can be seen from the figure that the amplitude of the PI-R controller's control strategy curve at $0 \mathrm{~Hz}$ and $300 \mathrm{~Hz}$ is basically equal to $0 \mathrm{~dB}$, indicating that the PI-R controller can make the DC value and the 6 times frequency $\mathrm{AC}$ value of the rotor current track the $\mathrm{DC}$ value and the 6 times frequency $\mathrm{AC}$ value respectively, and the amplification gain is approximately equal to 1 . However, PI controller can only implement floating control to the DC component of rotor current, but can do nothing with 6 times frequency AC component. Therefore, PI-R current controller in dq reference frame can effectively control the fundamental wave and the 5 th and 7 th harmonic components.

\section{Simulation results and conclusions}

In PSCAD, the modeling and simulation of the unimproved and improved control strategies of the machine-side converter of PI-R current controller based on $\mathrm{dq}$ reference frame are carried out respectively. The parameters of the doubly-fed wind power generation system used in simulation are shown in Table 1.

Table 1. The parameters of DFIG system

\begin{tabular}{lll}
\hline \multirow{2}{*}{$\begin{array}{l}\text { Wind turbine } \\
\text { parameters }\end{array}$} & Rated power: $1.5 \mathrm{MW}$ & Blade radius: $35 \mathrm{~m}$ \\
& Ari density: $1.225 \mathrm{~kg} / \mathrm{m}^{3}$ & Rated wind speed: $12 \mathrm{~m} / \mathrm{s}$ \\
& Cut in wind speed: $3 \mathrm{~m} / \mathrm{s}$ & Cut out wind speed: $25 \mathrm{~m} / \mathrm{s}$ \\
\hline \multirow{2}{*}{ DFIG parameters } & Rated power: $1.5 \mathrm{MVA}$ & Rotor stator ratio: 2.5 \\
& Number of pole pairs: 2 & Inertia constant: $1.14 \mathrm{~s}$ \\
\hline
\end{tabular}




\begin{tabular}{llll}
\hline & Stator resistance: $\quad R_{1}=0.00698 \Omega$ & Rotor resistance: $R_{2}=0.008252 \Omega$ \\
& Stator reactance: $\quad X_{1 \sigma}=0.05618 \Omega$ & Rotor reactance: $X_{2 \sigma}=0.036818 \Omega$ \\
& Mutual inductance: $\quad X_{m}=1.485432 \Omega$ \\
\hline \multirow{2}{*}{$\begin{array}{ll}\text { Converter } \\
\text { parameters }\end{array}$} & DC bus voltage: $1100 \mathrm{~V}$ & Operating frequency: $2 \mathrm{kHz}$ \\
& Grid side inductance: $8 \mathrm{mH}$ & Grid side resistance: $0.0003 \Omega$ \\
& DC storage capacitor: $8640 \mu \mathrm{F}$ & \\
\hline
\end{tabular}

In the simulation, the wind speed is kept unchanged at $6 \mathrm{~m} / \mathrm{s}$, DFIG operates in a sub-synchronous state, and the rotor speed is about $0.8 \mathrm{p}$.u. The stator reactive power instruction is 0Var. The distortion voltage of the power grid is composed of $4 \%$ th negative order harmonic components and 4\% 7th positive order harmonic components of. The harmonic distortion rate THD of the

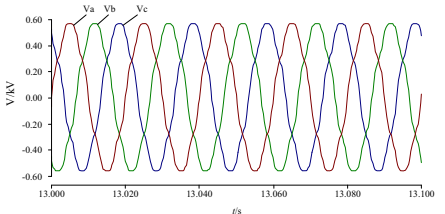

(a) the stator voltage power grid voltage is about $5.66 \%$. The parameters of PI$\mathrm{R}$ current controller refer to the design values in Section 4. Take Goal 1 as the control goal.

The simulation result of the control strategy of the machine-side converter of PI-R current controller based on dq reference frame is shown in Figure 8.
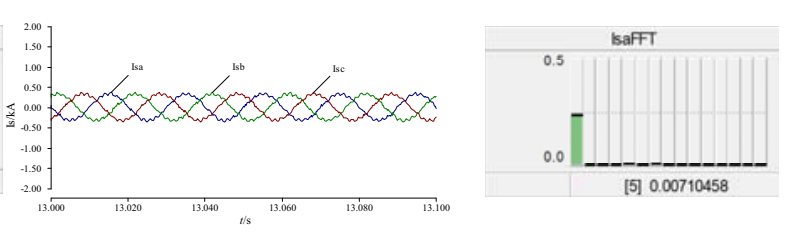

(b) the stator current
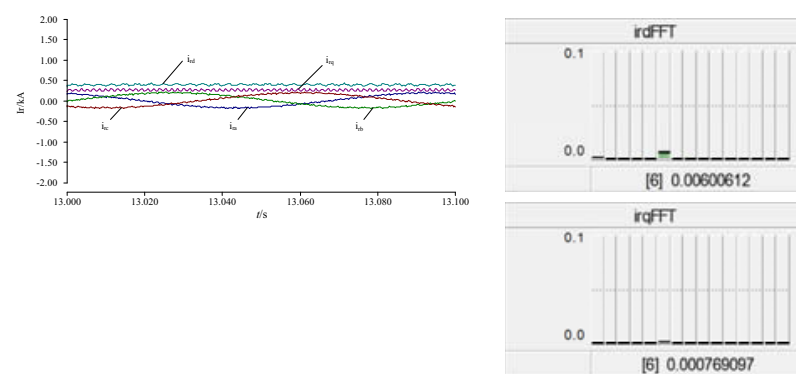

(c) the rotor current
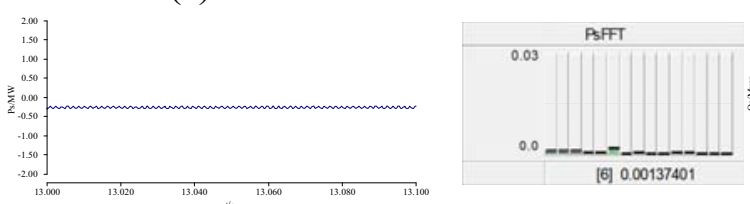

(e) the active stator power
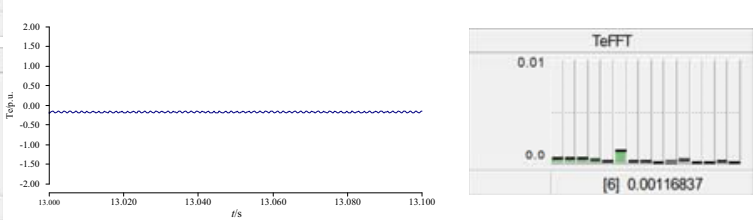

(d) the electromagnetic torque
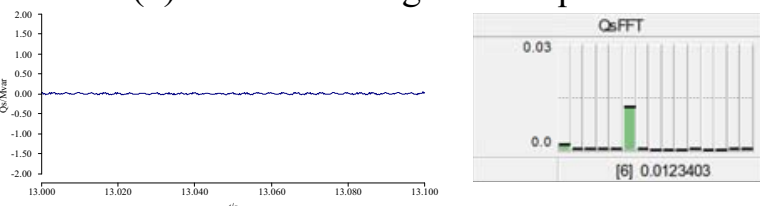

(f) the reactive stator power

Figure 8. the simulation result of the unimproved control strategy

The simulation result of the improved control strategy of the machine-side converter of PI-R current controller based on dq reference frame is shown in Figure 9.

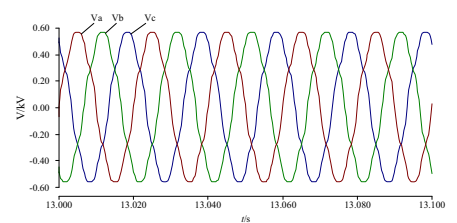

(a) the stator voltage

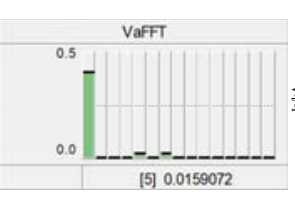

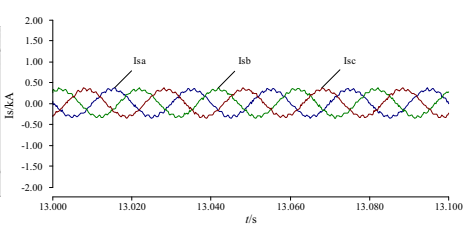

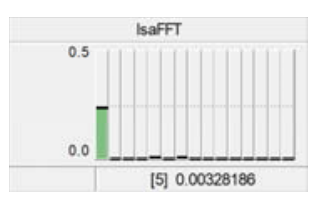

(b) the stator current 


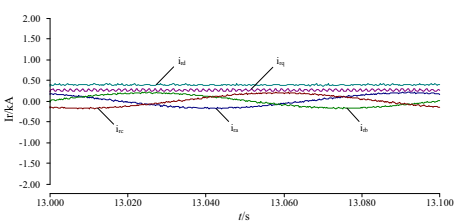

(c) the rotor current

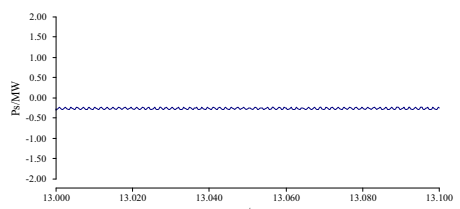

(e) the active stator power
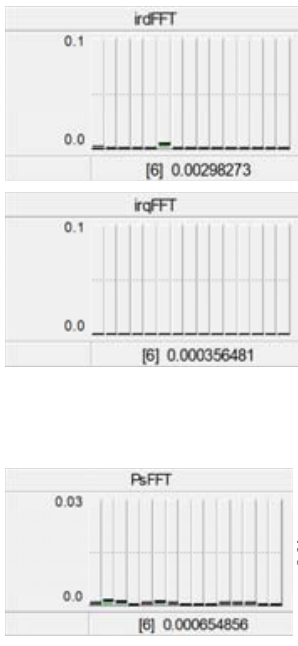

[6] 0.00035648

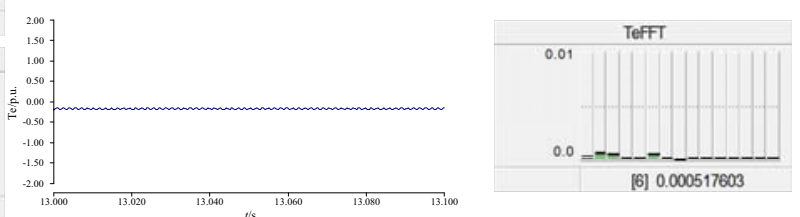

(d) the electromagnetic torque
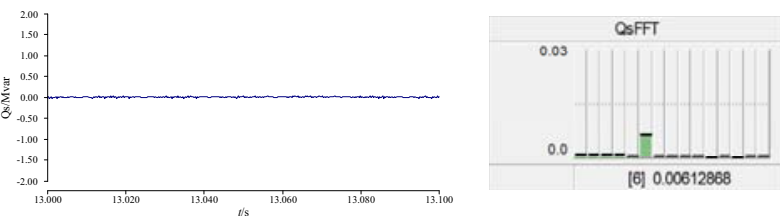

(f) the reactive stator power

Figure 9. the simulation result of the improved control strategy

By comparing FIG. 8 and FIG. 9, it can be seen that under the control objective of balanced stator current, the improved control strategy not only reduces the harmonic content of stator current compared with that of the unimproved control strategy, but also optimizes the equivalent values of rotor current, electromagnetic torque and active power.

\section{References}

1. IEEE Standard (1992) IEEE recommended practices and requirements for harmonic control in electrical power system. 519-1992.

2. HENSMAN G.(2002) Connecting nonlinear loads to public electricity systems: a guide to Engineering Recommendation G5/4.Power Engineering Journal,16(2):77-87.

3. GB/T 14549-93 Power quality Public Grid Harmonics.(1993).

4. Liu Changjin (2012) Resonant control for doublyfed wind turbines converter adapted to grid environment . Hangzhou: Zhejiang University.

5. Trinh Q N, Lee H H. (2011) Improvement of current performance for grid connected converter under distorted grid condition.
6. Yaojun, Guo Lisha, etc. (2016) Controllable Operation Area and control Strategy of doublyfed wind farm under voltage Imbalance from SI 'an network. Journal of electrical technology, 31(20) : 181-191.

7. HU JB, ZHANG W, WANG H S, et al. (2009) Proportional integral plus multi-frequency resonant current controller for grid connected voltage source converter under imbalanced and distorted supply voltage conditions. Journal of Zhejiang University: Science A,10(10):1532-1540.

8. $\mathrm{Xu}$ Hailiang, Hu Jiabing, He Yikang. (2011) Modeling and Control of Doubly fed Induction Generator under harmonic conditions. Power system automation, 35(11) : 20-81.

9. Miret J, Castilla M, Matas J, et al. (2009) Selective Harmonic-Compensation Control for Single-Phase Active Power Filter With High Harmonic Rejection. Industrial Electronics, IEEE Transaction on, 56(8): 3117-3127.

10. Ruan Yi, Chen Boshi.(2010) Automatic control system for electric drag: motion control system. Machinery Industry Press, Beijing. 